\title{
Classic maple syrup urine disease
}

INSERM

\section{Source}

INSERM. (1999). Orphanet: an online rare disease and orphan drug data base. Classic maple syrup urine disease. ORPHA:268145

Classic maple syrup urine disease (classic MSUD) is the most severe and probably common form of MSUD (see this term) characterized by a maple syrup odor in the cerumen at birth, poor feeding, lethargy and focal dystonia, followed by progressive encephalopathy and central respiratory failure if untreated. 